\title{
QUALIDADE INDUSTRIAL DE CULTIVARES DE TRIGO E TRITICALE SUBMETIDOS À ADUBAÇÃO NITROGENADA NO SISTEMA DE PLANTIO DIRETO ( $\left.{ }^{1}\right)$
}

\author{
DISNEI AMÉLIO CAZETTA $\left({ }^{2 *}\right)$; DOMINGOS FORNASIERI FILHO $\left({ }^{3}\right)$; ORIVALDO ARF $\left({ }^{4}\right)$; \\ ROGÉRIO GERMANI $\left({ }^{5}\right)$
}

\begin{abstract}
RESUMO
O presente trabalho foi desenvolvido nos anos agrícolas de 2004 e 2005, no município de Selvíria (MS), com o objetivo de avaliar a influência de doses de nitrogênio $(\mathrm{N})$ em cobertura nas características industriais de cultivares de trigo e triticale, em sistema de plantio direto. O delineamento experimental foi o de blocos ao acaso, com parcelas subdivididas, com 30 tratamentos constituídos pela combinação de seis cultivares nas parcelas, sendo cinco cultivares de trigo (IAC 364, IAC 370, Embrapa 22, BRS 210 e BRS 207) e um de triticale (IAC 3), e cinco doses de N em cobertura $\left(0,30,60,90\right.$ e $\left.120 \mathrm{~kg} \mathrm{ha}^{-1}\right)$ nas subparcelas, com quatro repetições. Em função dos resultados obtidos, o peso hectolítrico do triticale foi inferior ao dos cultivares de trigo, com a adubação nitrogenada proporcionando redução nesse componente; o número de queda foi adequado, sendo pouco afetado pela adubação nitrogenada; a relação P/L da farinha, de forma geral foi elevada, podendo prejudicar a aceitação comercial de farinha para panificação; a adubação nitrogenada em cobertura incrementou a força geral do glúten $(W)$, bem como o teor de proteína da farinha e reduziu a relação $\mathrm{P} / \mathrm{L}$, influenciando positivamente na qualidade da farinha para panificação; a farinha de triticale não foi adequada para fins de panificação, por sua reduzida força geral do glúten.
\end{abstract}

Palavras-chave: Triticum aestivum, Triticosecale, irrigação, glúten, proteína.

\section{ABSTRACT}

\section{INDUSTRIAL QUALITY IN CULTIVARS OF WHEAT AND TRITICALE SUBMITTED TO THE NITROGEN FERTILIZATION IN NO-TILL SYSTEM}

The work was developed in season cropping 2004 and 2005 in Selvíria county (MS), Brazil, with aim of evaluate the effect of different rates of nitrogen $(\mathrm{N})$ in side dress on the industrial characteristics of the cultivars of wheat and triticale in no-till system. The completely randomize design was used with split plots with 30 treatments, consisting of the six combination of cultivars in plots, being five cultivars of wheat (IAC 364, IAC 370, Embrapa 22, BRS 210 and BRS 207) and one of triticale (IAC 3), and five rates of $\mathrm{N}$ in side dress (0, 30, 60, 90 and $\left.120 \mathrm{~kg} \mathrm{ha}^{-1}\right)$ in subplots, with four replicatons. In function of the results gotten, the hectoliter weight of triticale was inferior to the ones of the wheat, with the nitrogen fertilization providing reduction in this component; the falling number is adjusted, not being affected for the nitrogen fertilization; relation $\mathrm{P} / \mathrm{L}$ of the flour of general form is raised, harming the commercial flour acceptance for bread-making; the nitrogen fertilization in covering develops the gluten strength (W) as well as the protein content of the flour and reduces relation P/L positively, influencing in the quality of the flour for breadmaking; the flour of triticale is not adjusted for end of bread-making for its reduced gluten strength.

Key words: Triticum aestivum, Triticosecale, irrigation, gluten, protein.

(1) Parte do trabalho de Mestrado do primeiro autor. Recebido para publicação em 11 de setembro de 2006 e aceito 31 de março de 2008.

$\left({ }^{2}\right)$ Doutorando, Departamento de Produção Vegetal - Universidade Estadual Paulista - UNESP, Via de Acesso Prof. Paulo Donato Castellane, s/n, 14884-900 Jaboticabal (SP). E-mail: disnei@fcav.unesp.br. (*) Autor correspondente.

$\left({ }^{3}\right)$ Departamento de Produção Vegetal, Universidade Estadual Paulista - UNESP, 14884-900 Jaboticabal (SP). E-mail: fornasieri@fcav.unesp.br

$\left({ }^{4}\right)$ Departamento de Fitotecnia, Economia e Sociologia Rural - Universidade Estadual Paulista - UNESP, Caixa Postal 31, 15385-000 Ilha Solteira (SP). E-mail: arf@agr.feis.unesp.br

$\left({ }^{5}\right)$ Embrapa Agroindústria de Alimentos - Av. das Américas, 29501 - Bairro Guaratiba, 23020-470 Rio de Janeiro (RJ). E mail: germani@ctaa.embrapa 


\section{INTRODUÇÃO}

As condições ambientais (solo, clima, e outros) influenciam no comportamento dos genótipos e nas características dos grãos do trigo e da farinha, além de determinar a aptidão da espécie para os diferentes usos industriais (Bequete, 1989 citado por GUARIENTI et al., 2000). De todos os produtos derivados do trigo, a farinha é a mais importante devido aos seus múltiplos usos (Guarienti, 1993). A farinha de trigo para a panificação deve apresentar características como alta capacidade de absorção de água, boa tolerância ao amassamento, glúten de força média a forte e alta porcentagem de proteína. Uma vez atendidos esses requisitos, tem-se alta potencialidade de produzir pão de boa qualidade (Schroeder, s.d. citado por SOAVE e Freitas, 1996).

Para avaliar a qualidade dos grãos e da farinha de trigo, MANDARINO (1993) sugeriu, entre outras análises físicas, o peso hectolítrico e a massa de mil grãos, físico-químicas - o teor de proteína e o número de queda e as análises tecnológicas de alveografia, cujas principais medidas são a extensibilidade, a tenacidade e a força geral do glúten. A extensibilidade (L) é um indicativo do volume que a massa pode atingir e a tenacidade $(P)$ é um indicativo da pressão máxima de ruptura da massa. Segundo MANDARINO (1994), o aumento da relação P/ $\mathrm{L}$, com conseqüente acréscimo da elasticidade do glúten, pode ser provocado pela elevação do teor de gluteninas, que são proteínas de elevada elasticidade e baixa extensibilidade. Por outro lado, a redução da relação $\mathrm{P} / \mathrm{L}$ pode ser explicada pelo aumento do teor de gliadinas, que são responsáveis por baixa elasticidade do glúten. A força geral de glúten (W) é indicativo da força de panificação da farinha. De acordo com MANDARINO (1993), valores de W superiores a $200 \times 10^{-4} \mathrm{~J}$ revelam trigo com força melhoradora; entre 100 e $200 \times 10^{-4} \mathrm{~J}$ com força média; e inferiores a $100 \times 10^{-4} \mathrm{~J}$, com força fraca (glúten fraco). Por outro lado, para Rosa e Rosa FiLHo (1998), trigo com valores de $\mathrm{W}$ maiores que $300 \times 10^{-4} \mathrm{~J}$ é considerado forte; trigo com valores de $\mathrm{W}$ menores que $150 \times 10^{-4} \mathrm{~J}$ é considerado fraco e, para a produção de pão francês, o valor de $\mathrm{W}$ deve estar entre 180 e $200 \times 10^{-4} \mathrm{~J}$.

O número de queda (Falling Number) ou de Hagberg caracteriza as farinhas de trigo quanto à atividade das amilases, permitindo, assim, prever seu comportamento durante a etapa de fermentação da massa no processo de panificação. Por meio desse índice pode-se estimar a capacidade de fermentação que a massa de uma determinada farinha possui. A classificação, de acordo com MANDARINO (1993), é a seguinte: trigo com hiperatividade amilásica (60-70 segundos); alta atividade amilásica (70-150 segundos); atividade amilásica média (150-200 segundos); baixa atividade amilásica (200-400 segundos) e atividade amilásica insuficiente (mais de 400 segundos). De acordo com Mandarino (1993), trigos com hiperatividade amilásica contêm, na amostra, grãos germinados (dificultando o processo de panificação) e aqueles com baixa atividade amilásica possuem muito pouco ou nenhum grão germinado na amostra (melhorando o processo de panificação).

Segundo BRASIL (1999), as cultivares de trigo estão classificadas (de acordo com a alveografia e o número de queda) em cinco classes, ou seja: na classe de trigo brando são enquadrados grãos de cultivares aptas para a produção de bolos, bolachas (biscoitos doces), produtos de confeitaria, pizzas e massa do tipo caseira fresca, com força geral do glúten $(W)^{3} 50 x$ $10^{-4} \mathrm{~J}$ e número de queda de ${ }^{3} 200$ segundos. A classe de trigo para pão envolve grãos de cultivares com aptidão para a produção do tradicional pãozinho (do tipo francês ou d'água) consumido no Brasil. Esse trigo também pode ser utilizado para a produção de massas alimentícias secas, de folhados ou em uso doméstico, dependendo de suas características de força de glúten $(\mathrm{W})$, com $\mathrm{W}^{3} 180 \times 10^{-4} \mathrm{~J}$ e número de queda de ${ }^{3} 200$ segundos. A classe de trigo melhorador envolve grãos de cultivares aptos para mesclas com grãos de trigo brando, para fim de panificação, produção de massas alimentícias, biscoito do tipo crackers e pães industriais (pão de forma e pão para hambúrguer), com $\mathrm{W}^{3} 300 \times 10^{-4} \mathrm{~J}$ e número de queda de ${ }^{3} 250$ segundos. Na classe de trigo para outros usos, enquadram-se os grãos de cultivares destinadas à alimentação animal ou outro uso industrial, envolvendo os grãos de cultivares de trigo com qualquer valor de $W$, mas não enquadrados em nenhuma das outras classes, por terem número de queda inferior a 200. Na classe do trigo durum, especificamente os grãos da espécie Triticum durum L., estão os grãos de cultivares para a produção de massas alimentícias secas (do tipo italiana), com número de queda mínimo de 250 , sem especificação do valor de $W$.

De acordo com Peltonen (1992), a concentração de proteínas nos grãos do trigo é um dos principais fatores determinantes da qualidade. O teor e a qualidade das proteínas são especialmente afetados pelas diferenças ambientais como clima, irrigação, temperatura, fertilidade, mobilidade do nutriente no solo e na planta e disponibilidade de nitrogênio no solo (Olson, 1979 citado por Coelho et al., 2001). SOARES SOBRINHO (1999) observou que as características físico-químicas e reológicas mais influenciadas positivamente pela adubação nitrogenada foram teor protéico e força de glúten. 
GUARIENTI et al. (2000) avaliaram o efeito de sistemas de manejo do solo e de rotação de culturas nas características que definem a qualidade industrial de trigo e observaram que o preparo convencional de solo com arado de disco e o cultivo mínimo reduzem o número de queda, quando comparado com o plantio direto, representando grande prejuízo ao agricultor. Este é um dos critérios de classificação comercial da farinha (BRASIL, 1999), haja vista ser o sistema de plantio direto uma alternativa para minimizar esse problema.

A influência do sistema de plantio direto, da adubação nitrogenada, a recomendação de cultivares adaptadas ao cultivo do trigo e do triticale, visando à obtenção de farinha com qualidade industrial sob condições ambientais da região tritícola do CentroOeste brasileiro, sob baixa altitude e inverno seco, são importantes, pois, se viável, ter-se-á nova opção de cultivo. O trabalho tem por objetivo avaliar a influência de diferentes doses de nitrogênio em cobertura sobre as características industriais de cinco cultivares de trigo e um de triticale em Selvíria (MS), no sistema de plantio direto.

\section{MATERIAL E MÉTODOS}

O trabalho foi desenvolvido nos anos agrícolas de 2004 e 2005, em Sevíria (MS), situada a aproximadamente $51^{\circ} 22^{\prime}$ de longitude Oeste de Greenwich e $20^{\circ} 22^{\prime}$ de latitude Sul, com altitude de 335 metros, em um Latossolo Vermelho distrófico típico argiloso (EMBRAPA, 1999). A classificação climática de acordo com Köppen é Aw, com precipitação média anual de $1.370 \mathrm{~mm}$ e umidade relativa do ar média anual variando entre $70 \%$ e $80 \%$. A temperatura média anual é de $23,5^{\circ} \mathrm{C}$, a média dos meses mais quentes (janeiro e fevereiro) é $25,7^{\circ} \mathrm{C}$ e a dos mais frios (junho e julho) é $20,6^{\circ} \mathrm{C}$. Os dados de precipitação pluvial e de temperatura relativos aos períodos em que os experimentos estavam no campo estão apresentados na figura 1.

As características químicas do solo na profundidade de 0 a $20 \mathrm{~cm}$, determinadas antes da instalação dos experimentos, de acordo com método de RAIJ e QuAGGio (1983), foram representadas por: $\mathrm{pH}$ $\left(\mathrm{CaCl}_{2}\right)=4,7 ; \mathrm{MO}=19 \mathrm{~g} \mathrm{dm}^{-3} ; \mathrm{P}($ resina $)=27 \mathrm{mg} \mathrm{dm}^{-}$ 3; 2,8; 25; 16 e $43 \mathrm{mmol}_{\mathrm{c}} \mathrm{dm}^{-3}$, respectivamente, de $\mathrm{K}$, $\mathrm{Ca}, \mathrm{Mg}$ e H + Alcom $51 \%$ de saturação por bases (V).

O delineamento experimental foi o de blocos ao acaso com parcelas subdivididas, com 30 tratamentos constituídos pela combinação de seis cultivares nas parcelas, sendo cinco de trigo e um de triticale, e cinco doses de $\mathrm{N}$ em cobertura $(0,30,60$, 90 e $120 \mathrm{~kg} \mathrm{ha}^{-1}$ ) nas subparcelas, com quatro repetições. Cada subparcela foi representada por 11 linhas na safra 2004 e 13 linhas na safra 2005, com 6,0 m de comprimento, espaçadas $17 \mathrm{~cm}$ uma da outra, considerando-se como área útil as cinco linhas centrais, desprezando-se $0,5 \mathrm{~m}$ em ambas as extremidades.

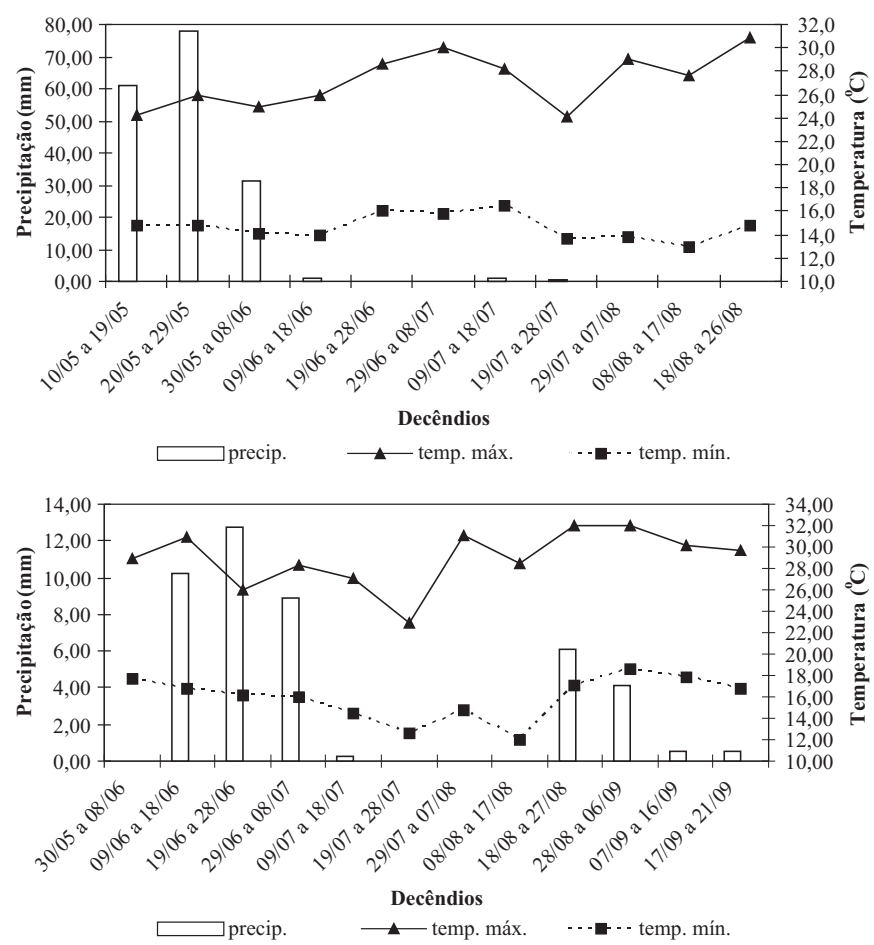

Figura 1. Dados meteorológicos por decêndios da fazenda de ensino e pesquisa da UNESP de Ilha Solteira (SP), safra 2004 (A) e 2005 (B), durante o período experimental.

Aproximadamente duas semanas antes da semeadura de ambos os experimentos, realizou-se a dessecação dos restos culturais da cultura antecessora (milho) e de eventuais plantas invasoras com gliphosate (1.560 $\mathrm{g} \mathrm{ha}^{-1}$ do i.a).

A semeadura foi realizada em 10 de maio de 2004 e 30 de maio de 2005, no sistema de plantio direto, utilizando as cultivares de trigo IAC 364 Tucuruí III (ciclo médio, altura baixa, classe de trigo melhorador), IAC 370 - Armageddon (ciclo médio, altura média, classe de trigo pão), Embrapa 22 (ciclo precoce, altura média, trigo pão), BRS 210 (ciclo médio, altura baixa, trigo melhorador), BRS 207 (ciclo médio, altura baixa, trigo pão) e o cultivar de triticale IAC 3Banteng (ciclo precoce, altura alta, farinha da classe de trigo brando), sendo realizadas as irrigações necessárias após a semeadura de acordo com EMBRAPA (2003). Utilizou-se na semeadura o número de sementes necessário para obtenção de 300 a 350 plantas por metro quadrado. 
As sementes foram, previamente à semeadura, tratadas com thiodicarb $(600 \mathrm{~g}$ do i.a. por $100 \mathrm{~kg}$ de sementes), visando, principalmente, ao controle de cupins (Synterms molestus, Procorniterms striatus e Cornitermes leslesii) e da lagarta-elasmo (Elasmopalpus lignosellus) em associação com óxido de zinco $(500 \mathrm{~g}$ do i.a. por $100 \mathrm{~kg}$ de sementes) para fornecimento de zinco, além de $5 \mathrm{~g}$ de $\mathrm{Mo}+1 \mathrm{~g}$ de B por $100 \mathrm{~kg}$ de sementes. A emergência das plântulas ocorreu aos seis dias após a semeadura em ambos os anos.

Durante a realização do experimento, na safra 2004, foram aplicados $280 \mathrm{~g}$ de i.a. $\mathrm{ha}^{-1}$ de dimethoate, para controle de pulgões da parte aérea, e $1 \mathrm{~L} \mathrm{ha}^{-1}$ de tebuconazole para o controle de fungos da parte aérea. $\mathrm{Na}$ safra de 2005, foram feitas duas aplicações de $280 \mathrm{~g}$ do i.a. ha ${ }^{-1}$ de dimethoate e uma aplicação de 1 $\mathrm{L} \mathrm{ha}^{-1}$ de tebuconazole.

A adubação de semeadura em ambas as safras foi constituída por $10 \mathrm{~kg} \mathrm{ha}^{-1}$ de $\mathrm{N}$ (Uréia), $62,5 \mathrm{~kg}$ ha $^{-1}$ de $\mathrm{P}_{2} \mathrm{O}_{5}$ (Super simples), $37,5 \mathrm{~kg} \mathrm{ha}^{-1}$ de $\mathrm{K}_{2} \mathrm{O}$ (Cloreto de potássio) e 1,25 $\mathrm{kg} \mathrm{ha}^{-1}$ de Zn (Sulfato de zinco), de acordo com as recomendações de adubação para o trigo e triticale irrigados (CAMARGO et al., 1997). A fonte de $\mathrm{N}$ em cobertura foi o nitrato de amônio, aplicado a lanço aos 26 e 22 dias após a emergência nas safras de 2004 e 2005 respectivamente, no início do perfilhamento (Feeks 3.0); após a adubação nitrogenada, realizou-se a irrigação por aspersão.

O sistema de irrigação utilizado foi por aspersão, por meio de pivô central, se o manejo da lâmina d'água foi efetuado por meio de tensiômetros do tipo vacuômetro, instalados a 10 e a $30 \mathrm{~cm}$ de profundidade dentro da área experimental, e a curva característica de retenção de água do solo de 6 a 1500 $\mathrm{kPa}$, utilizando a tensão média de água no solo, no momento das irrigações, de $40 \mathrm{kPa}$, de acordo com recomendações da EMBRAPA (2003).

Nas duas safras, fez-se aplicação de herbicida pós-emergente á base de metsulfuron methyl $\left(5 \mathrm{~g} \mathrm{ha}^{-1}\right.$ do produto comercial) e de diclofop methyl (1,3 $\mathrm{L} \mathrm{ha}^{-}$ 1 do produto comercial), para controle, respectivamente, de folhas largas e gramíneas.

Ao final do ciclo da cultura foram colhidas as parcelas experimentais, sendo os grãos submetidos à secagem em ambiente protegido e controlado, até atingir 13\% de umidade (b.u.). A seguir procedeu-se às seguintes determinações:

- Número de grãos por espiga: foi determinado através da contagem dos grãos de 20 espigas coletadas ao acaso na área útil de cada unidade experimental.

- Peso Hectolítrico: a massa de 100 L de grãos foi determinada em balança especial modelo OHAUS, com teor de água dos grãos corrigido para 13\% de umidade (base úmida).

- Teor de proteína nos grãos (\%): foi determinado por meio da quantificação do teor de nitrogênio total, multiplicado por 5,7 (fator de conversão) para obter o valor correspondente ao teor de proteína, em porcentagem.

- Número de queda (Falling Number) ou de Hagberg: este teste tem por finalidade verificar a atividade da enzima alfa-amilase do grão, sendo dada pela medida do tempo, em segundos, que um "anel" leva para atravessar a suspensão gelatinizada de amido contida em um tubo de vidro.

- Teste de Alveografia: este teste fornece informações sobre as características da massa, como: extensibilidade $(\mathrm{L})$, tenacidade $(\mathrm{P})$ e força geral de glúten (W). É realizado no alveógrafo Chopin, utilizando-se de um pequeno disco feito com a massa, de circunferência e espessura uniformes, no qual inflase ar, sob pressão constante, para formação de uma bolha de massa, até sua ruptura. Por meio de um manômetro, registram-se as diferentes pressões, construindo-se uma curva chamada alveograma, na qual o comprimento da curva denomina-se extensibilidade $(\mathrm{L})$, sua altura, tenacidade $(\mathrm{P})$ e a área circunscrita pela curva, força geral do glúten (W).

A determinação do número de queda e os testes de alveografia foram feitos na Embrapa Agroindústria de Alimentos no Rio de Janeiro (RJ).

Os dados obtidos foram submetidos à análise de variância com o teste F. Quando alcançada a significância estatística, as médias dos cultivares foram comparadas pelo teste de Tukey a $5 \%$. Foram realizadas análises de regressão para as doses de $\mathrm{N}$, quando não haviam interações significativas com as cultivares, bem como regressão para as doses de $\mathrm{N}$ para cada cultivar, quando as interações eram significativas.

\section{RESULTADOS E DISCUSSÃO}

Todas as cultivares de trigo tiveram valores médios de peso hectolítrico adequados na safra 2004 (Tabela 1), enquadrando-se no tipo 1 (mínimo de 78 $\mathrm{kg} \mathrm{hl}^{-1}$ ), que é a massa padrão de comercialização. O mesmo não ocorreu na safra 2005, na qual apenas a IAC 370 enquadrou-se no Tipo 1, ficando as cultivares IAC 364, EMBRAPA 22, BRS 210 e BRS 207 no Tipo 2 (mínimo de $75 \mathrm{~kg} \mathrm{hl}^{-1}$ ); IAC 3 (triticale) ficou com o menor peso hectolítrico nas duas safras, enquadrando-se no Tipo 1 na safra 2004 e no Tipo 3 (mínimo de $70 \mathrm{~kg} \mathrm{hl}^{-1}$ ) na safra 2005. 
As reduções de peso hectolítrico na safra de 2005, em relação à de 2004, estão possivelmente relacionadas aos efeitos de temperaturas mais elevadas (Figura 1), interferindo na produção e na distribuição de fotoassimilados, provocando granação deficiente.

A adubação nitrogenada proporcionou uma redução linear de peso hectolítrico nas cultivares IAC 370, EMBRAPA 22, BRS 210 e BRS 207 na safra 2004 e em todas as cultivares na safra 2005 (Figuras $2 \mathrm{~b}$ e 2c), confirmando os resultados obtidos por FrIZONE et al. (1996), CoelHo et al. (1998) e CAMARgo et al. (1988). Nas duas safras, na cultivar de trigo IAC 370 , em média, observou-se a maior e na de triticale (IAC 3), o menor peso hectolítrico com o incremento nas doses de $\mathrm{N}$ em cobertura (Figuras 2b e 2c); na safra 2004, a adubação nitrogenada não influenciou nesse componente o triticale (IAC 3). A massa hectolítrica do IAC 364 ajustou-se a uma equação quadrática na safra 2004 (Figura 2b), sendo necessários 45,2 kg ha${ }^{1}$ de N para atingir o valor máximo. Loewy (1990), Pereira et al. (1991) e SoAres Sobrinho (1999), por outro lado, não observaram a influência da adubação nitrogenada nesse componente.

A redução da massa hectolítrica com o incremento das doses de $\mathrm{N}$, na maioria das cultivares pode estar relacionada ao aumento do número de grãos por espiga nas duas safras (Figura 2a). O aumento das doses de $\mathrm{N}$ provocou a formação de grãos pequenos, enrugados e malformados, pelo enchimento deficiente. As correlações negativas observadas entre massa hectolítrica e o número de grãos por espiga $\left(-0,47^{* *}\right.$ e $-0,66^{* *}$ nas safras de 2004 e 2005 respectivamente) comprovam esse fato.

Observando o teor de proteína nos grãos, na média, nas cultivares de trigo EMBRAPA 22, IAC 364 e BRS 210 observaram-se maiores teores nas duas safras, e IAC 3 (triticale) esteve entre as de maior teor na segunda safra e a de menor valor na primeira (Tabela 1). Na safra de 2004, o teor de proteína dos grãos de todas as cultivares aumentou linearmente com a adubação nitrogenada (Figura 2d). Na safra de 2005 , independentemente das cultivares, a adubação nitrogenada aumentou linearmente o teor de proteína nos grãos (Figura 2e). SOARES SOBRINHO (1999) também verificou aumento no teor de proteína nos grãos, passando de 10,76 para 13,01 \%, quando a dose de $\mathrm{N}$ variou de 0 a $120 \mathrm{~kg} \mathrm{ha}^{-1}$. Vários outros autores indicam aumentos do teor protéico nos grãos com o aumento das doses de N, como CAMARGo et al. (1988), Puri et al. (1989), Cooper e Blakeney (1990), Borgui et al. (1994) e GUARIENTI et al. (1994b).

Com relação ao número de queda, que mede a atividade da alfa-amilase, na média, verificou-se nas cultivares BRS 210 e EMBRAPA 22, o maior número de queda nas duas safras e em IAC 3 (triticale), o menor número (Tabela 2). Esse fato demonstra, que o triticale possui menor atividade da enzima alfaamilase, ou seja, provavelmente indicadormência fisiológica após a maturidade fisiológica inferior à das cultivares de trigo. De acordo com MANDARINO (1993), as cultivares BRS 210, EMBRAPA 22, IAC 370, IAC 364 e BRS 207 seriam classificadas como trigos de atividade amilásica insuficiente e o IAC 3 (triticale), como de baixa atividade enzimática. Assim, as cultivares proporcionaram bem pouco ou nenhum grão germinado na amostra, demonstrando que a cultura não foi submetida a condições de excesso de chuva após a maturação fisiológica dos grãos. Trigos germinados, ou em vias de germinar, possuem atividade amilásica extremamente elevada, liqüefazem a massa, dificultando o processo de panificação, ou até mesmo impedindo-o em casos extremos (MANDARINO, 1993).

$\mathrm{Na}$ safra 2004, as doses de $\mathrm{N}$ não influenciaram no número de queda das cultivares IAC 3, IAC 370 e EMBRAPA 22; entretanto, para as cultivares IAC 364 e BRS 207, a adubação nitrogenada ocasionou incremento linear neste componente (Figura 3a). GUARIENTI et al. (1994b) verificaram que a atividade enzimática é reduzida com o aumento das doses de $\mathrm{N}$; já para a cultivar BRS 210 o ajuste obtido foi quadrático (Figura 3a), com a dose de $53,8 \mathrm{~kg} \mathrm{ha}^{-1}$ de $\mathrm{N}$ resultando em maior número de queda. Na safra 2005 , no triticale (IAC 3) ocorreram os menores valores do número de queda, com redução linear com o aumento da dose de N, e o BRS 207, aumento linear (Figura 3b). Para as cultivares IAC 370 e BRS 210, o número de queda ajustou-se a equações quadráticas, com as doses de 58,1 e 20,7 $\mathrm{kg} \mathrm{ha}^{-1}$ de $\mathrm{N}$ apresentando o valor mínimo, respectivamente. Para as demais cultivares, o número de queda também se ajustou a equações quadráticas, porém, as doses de 96 e 83,8 $\mathrm{kg} \mathrm{ha}^{-1}$ de $\mathrm{N}$ resultaram em valor máximo (Figura $3 \mathrm{~b}$ ). Verifica-se, de forma geral, que a adubação nitrogenada interfere de forma positiva ou negativa na atividade da alfa-amilase, dependendo da cultivar utilizada e da dose de $\mathrm{N}$ aplicada em cobertura.

Quanto à relação P/L, na safra de 2004, o triticale (IAC 3) foi a de maior valor. Na safra de 2005, as maiores relações foram obtidas para as cultivares IAC 364 e IAC 370 (Tabela 2). Na safra 2004, a adubação nitrogenada proporcionou redução linear da relação P/L nas cultivares IAC 364 e BRS 207; para as cultivares IAC 370 e BRS 210 os ajustes foram quadráticos (Figura 3c), com as doses de 100,8 e 105,2 $\mathrm{kg} \mathrm{ha}^{-1}$ de $\mathrm{N}$ apresentando a menor relação $\mathrm{P} / \mathrm{L}$, respectivamente. 
Tabela 1. Número de grãos por espiga, peso hectolítrico e teor de proteína nos grãos de cultivares de trigo e de triticale em função das doses de nitrogênio em cobertura. Selvíria (MS), Safras de 2004 e 2005

\begin{tabular}{|c|c|c|c|c|c|c|}
\hline \multirow{2}{*}{ Tratamentos } & \multicolumn{2}{|c|}{ Grãos por espiga } & \multicolumn{2}{|c|}{ Peso hectolítrico } & \multicolumn{2}{|c|}{ Teor de proteína } \\
\hline & 2004 & 2005 & 2004 & 2005 & 2004 & 2005 \\
\hline & 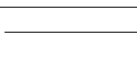 & 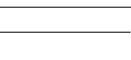 & 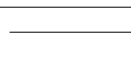 & $\overline{-}$ & 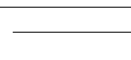 & \\
\hline \multicolumn{7}{|l|}{ Cultivar (C) } \\
\hline IAC 3 & $49,8 \mathrm{a}$ & 54,6 a & $79,2 \mathrm{c}$ & $71,3 \mathrm{c}$ & $13,28 \mathrm{c}$ & $13,94 \mathrm{ab}$ \\
\hline IAC 364 & $39,4 \mathrm{c}$ & $41,7 \mathrm{bc}$ & $81,9 \mathrm{~b}$ & $77,3 \mathrm{~b}$ & $15,94 \mathrm{a}$ & $14,69 \mathrm{a}$ \\
\hline IAC 370 & $42,3 \mathrm{bc}$ & $44,1 \mathrm{bc}$ & $84,0 \mathrm{a}$ & 79,0 a & $14,04 \mathrm{~b}$ & $12,59 \mathrm{~b}$ \\
\hline EMBRAPA 22 & 50,4 a & $44,4 \mathrm{bc}$ & $81,6 \mathrm{~b}$ & $76,9 \mathrm{~b}$ & 15,86 a & $13,85 \mathrm{ab}$ \\
\hline BRS 210 & $39,1 \mathrm{c}$ & $40,9 \mathrm{c}$ & $82,0 \mathrm{~b}$ & $76,4 \mathrm{~b}$ & $16,12 \mathrm{a}$ & $13,47 \mathrm{ab}$ \\
\hline BRS 207 & $44,6 \mathrm{~b}$ & $46,9 \mathrm{~b}$ & $82,4 \mathrm{~b}$ & $76,6 \mathrm{~b}$ & $14,49 \mathrm{~b}$ & $12,71 \mathrm{~b}$ \\
\hline Teste F (Cultivar) & $43,86^{* *}$ & $17,75^{* *}$ & $49,06^{* *}$ & $82,83^{* *}$ & $56,92^{* *}$ & $5,11^{* *}$ \\
\hline D.M.S. (Tukey a 5\%) & 3,42 & 5,43 & 1,02 & 1,30 & 0,72 & 1,62 \\
\hline \multicolumn{7}{|l|}{ Doses de $N\left(\mathrm{~kg} \mathrm{ha}^{-1}\right)(\mathrm{D})$} \\
\hline 0 & 42,4 & 41,8 & 83,0 & 77,5 & 13,08 & 11,63 \\
\hline 30 & 43,5 & 44,5 & 82,6 & 77,0 & 14,39 & 12,19 \\
\hline 60 & 44,4 & 46,5 & 81,8 & 76,3 & 15,17 & 13,53 \\
\hline 90 & 44,6 & 46,7 & 81,2 & 75,6 & 15,53 & 14,83 \\
\hline 120 & 46,3 & 47,6 & 80,7 & 74,7 & 16,61 & 15,52 \\
\hline Teste F (Doses de N) & $8,14^{* *}$ & $9,72^{* *}$ & 32,90 ** & $26,37^{* *}$ & $77,22^{* *}$ & $29,39^{* *}$ \\
\hline Teste F (Interação C x D) & $1,11^{\mathrm{NS}}$ & $1,21^{\mathrm{NS}}$ & $2,48^{* *}$ & $1,72 *$ & 2,96 ** & $1,61^{\mathrm{NS}}$ \\
\hline C.V. $(\%)_{\text {Cultivar }}$ & 7,52 & 11,62 & 1,2 & 1,7 & 4,7 & 11,6 \\
\hline C.V. $(\%)$ Doses de N & 5,62 & 8,08 & 1,0 & 1,4 & 4,9 & 11,1 \\
\hline
\end{tabular}

Médias seguidas da mesma letra não diferem entre si pelo teste de Tukey a $5 \%$ de probabilidade.

${ }^{*} \mathrm{e}^{* *}=$ significativo a $5 \%$ e $1 \%$ de probabilidade pelo teste $\mathrm{F}$ respectivamente. $\mathrm{NS}=$ não significativo.

Na safra de 2005, a adubação nitrogenada proporcionou uma diminuição linear da relação P/L nos cultivares IAC 370 e EMBRAPA 22, e para os cultivares IAC 364 e BRS 210 os ajustes foram quadráticos (Figura 3d), com as doses de 58 e 13,2 kg $\mathrm{ha}^{-1}$ de $\mathrm{N}$ apresentando as maiores relações $\mathrm{P} / \mathrm{L}$ respectivamente. Não foi observada influência de doses de $\mathrm{N}$ nessa relação para as cultivares IAC 3 e Embrapa 22 em 2004 e IAC 3 e BRS 207 na safra de 2005.

Apesar de as cultivares terem respondido de forma diferenciada à elevação das doses de $\mathrm{N}$ (Tabela 2), pode-se verificar, de maneira geral, que a relação $\mathrm{P} / \mathrm{L}$ é alta $(\geq 1,40)$, pois, de acordo com a classificação de GuARIEnti (1993), relação P/L menor que 0,6 é classificada como glúten extensível, relação $\mathrm{P} / \mathrm{L}$ de 0,6 a 1,2 como glúten balanceado, e relação $\mathrm{P} / \mathrm{L}$ maior que 1,21 como glúten tenaz. A relação $P / L$ alta $(\geq 1,40)$ significa farinha com alta elasticidade, ou seja, massa tenaz, o que resultará em pães de pequeno volume e duros. Segundo MANDARINO (1994), a elevada relação
P/L pode ser provocada pelo elevado teor de gluteninas, que são proteínas com elevada elasticidade e baixa extensibilidade. Temperaturas elevadas auxiliam na elevação de gluteninas resultando, assim, em farinha tenaz, o que pode ser observado, principalmente na safra de 2005, quando no período de granação (agosto/setembro), as temperaturas foram elevadas.

Com relação à força geral do glúten $(\mathrm{W})$, a cultivar IAC 364 destacou-se dos demais com a maior força geral do glúten na safra de 2004 e a cultivar BRS 210, sem se diferenciar do EMBRAPA 22, foi superior na safra de 2005. A IAC 3 (triticale) foi a de menor força geral do glúten nas duas safras (Tabela 2). De acordo com a classificação de MANDARINO (1993), para valores de $\mathrm{W}$, as cultivares IAC 364, EMBRAPA 22, IAC 370 e BRS 210 seriam, de forma geral, classificados como trigos com farinha de classe melhoradora, e o BRS 207 como farinha de classe pão. O triticale (IAC 3) seria classificado como trigo de força fraca (glúten fraco) nas duas safras. 

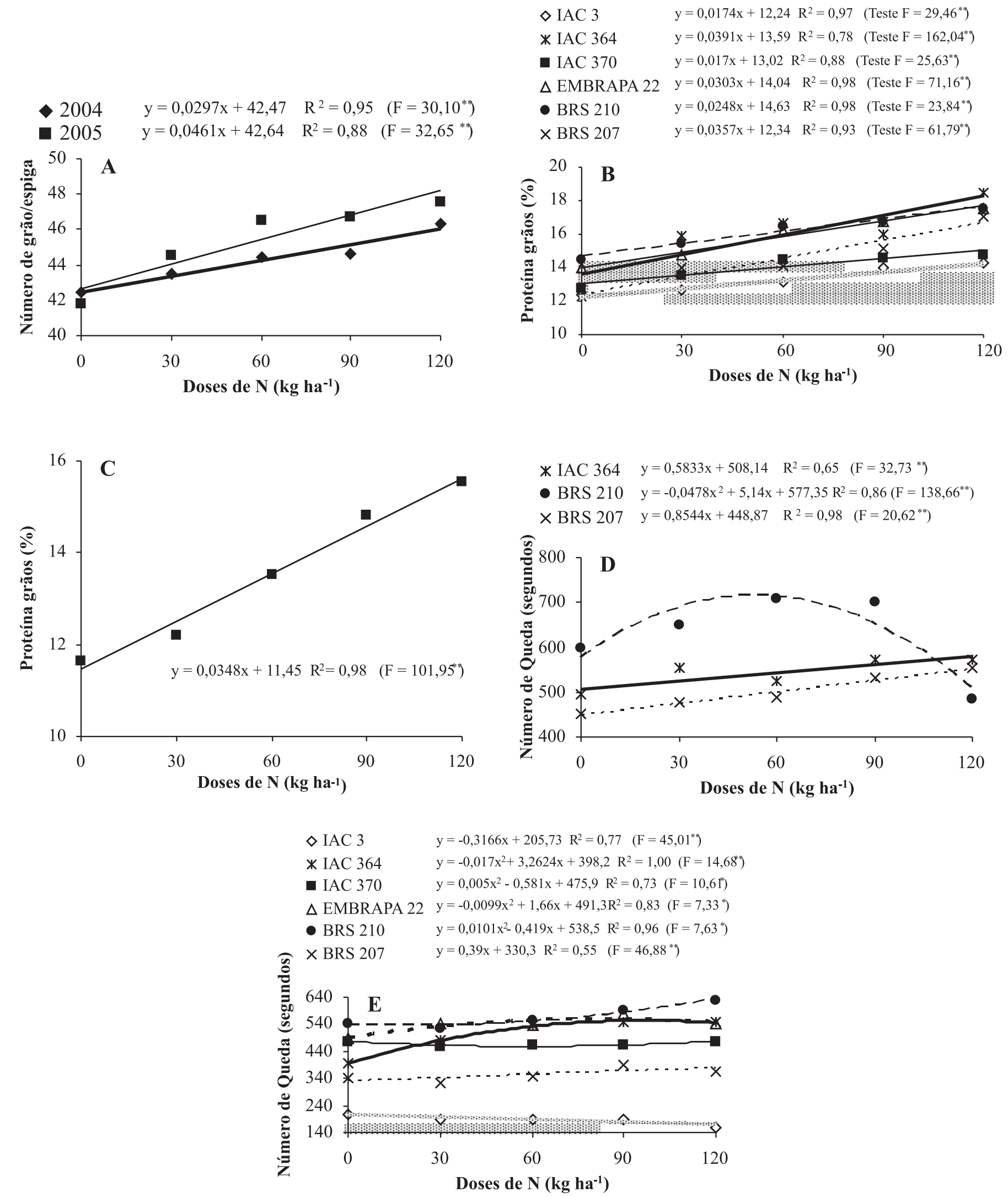

Figura 2. Número de grãos por espiga (A -safra 2004 e 2005), peso hectolítrico (B - safra 2004 e C - safra 2005) e teor de proteína nos grãos (D - safra 2004 e E - safra 2005) de cultivares de trigo e triticale em função das doses de nitrogênio $\left(\mathrm{kg} \mathrm{ha}^{-1}\right)$, em Selvíria (MS). 

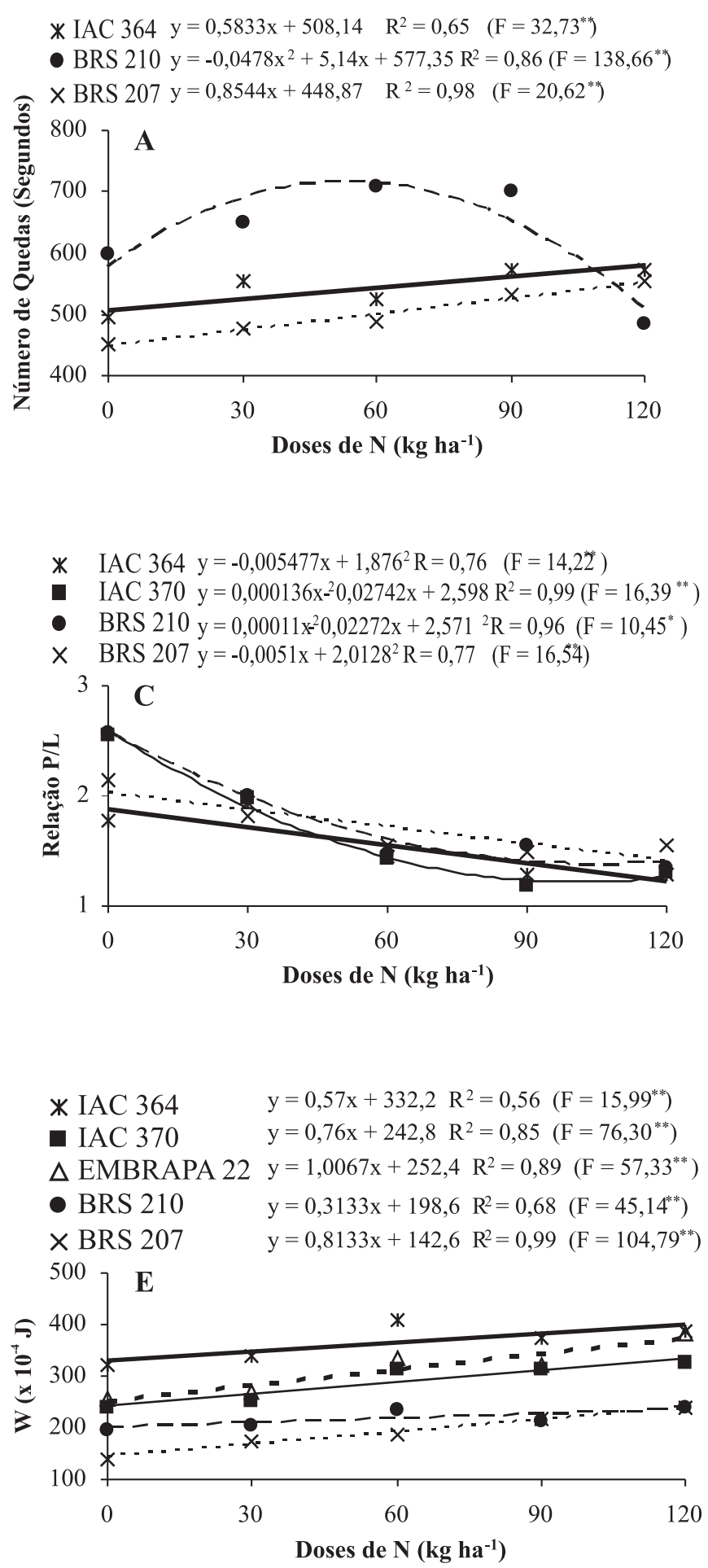

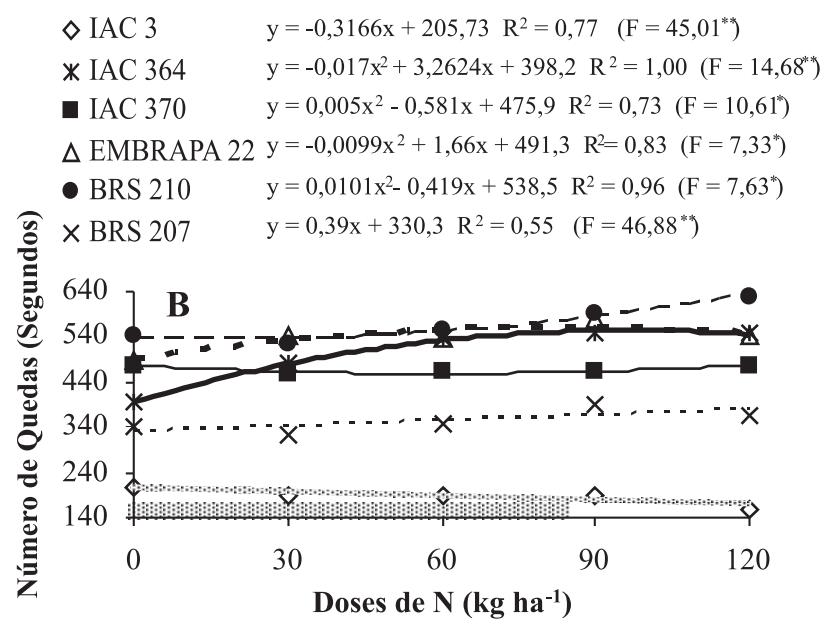

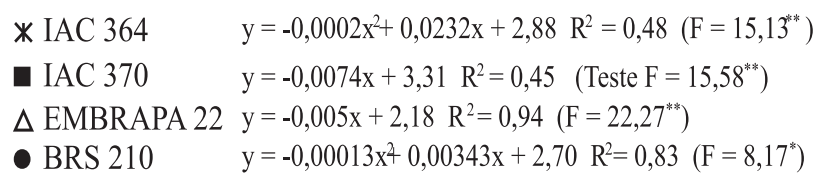
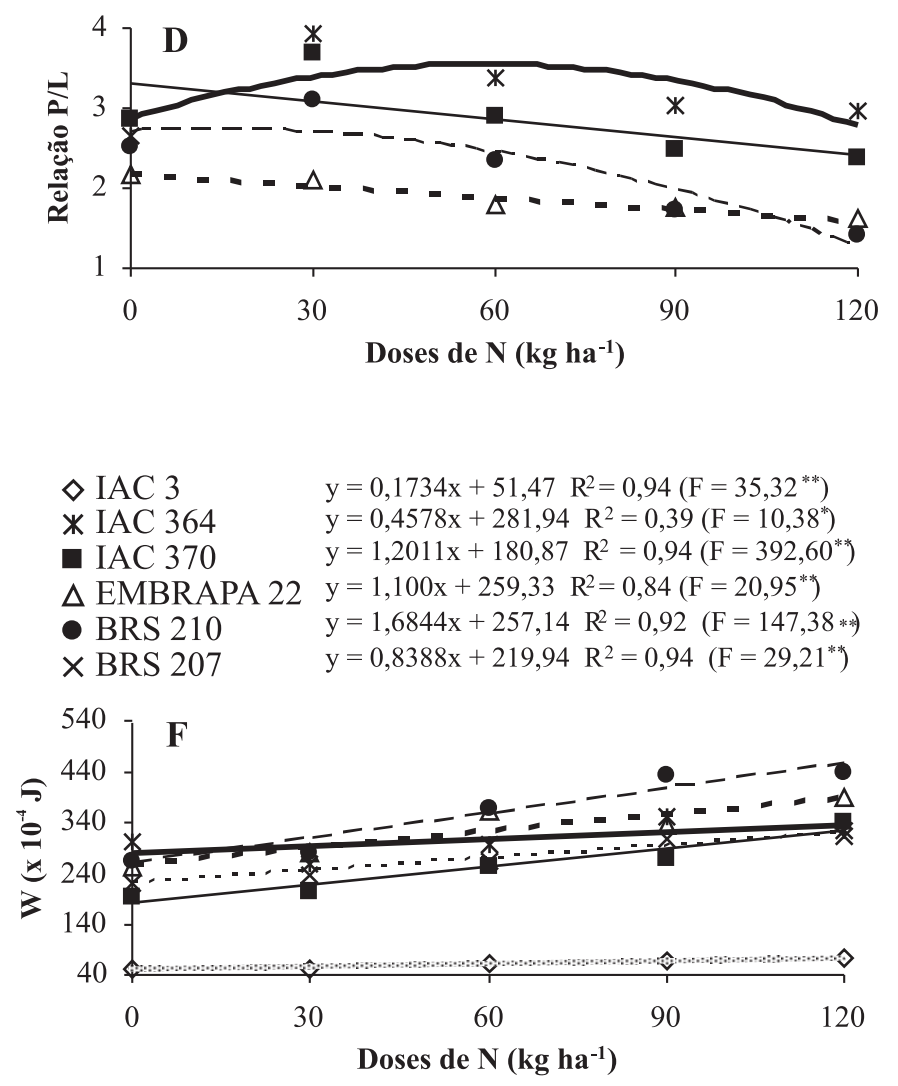

Figura 3. Número de queda (A - safra 2004 e B - safra 2005), relação P/L (C - safra 2004 e 3d - safra 2005) e força geral do glúten - W (E - safra 2004 e F - safra 2005) de cultivares de trigo e triticale em função das doses de nitrogênio, em Selvíria (MS). 
Tabela 2. Número de queda, relação $\mathrm{P} / \mathrm{L}$ e força geral do glúten (W) obtidos em grãos de trigo e triticale em função de cultivares e doses de nitrogênio em cobertura, em Selvíria (MS), Safras 2004 e 2005

\begin{tabular}{|c|c|c|c|c|c|c|}
\hline \multirow{3}{*}{ Tratamentos } & \multirow{2}{*}{\multicolumn{2}{|c|}{ Número de queda }} & \multicolumn{4}{|c|}{ Teste de Alveografia } \\
\hline & & & \multicolumn{2}{|c|}{ Relação P/L } & \multicolumn{2}{|c|}{$\mathrm{W}$} \\
\hline & 2004 & 2005 & 2004 & 2005 & 2004 & 2005 \\
\hline & 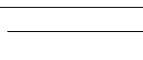 & $\bar{u}$ & 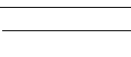 & 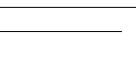 & $\longrightarrow$ & $T$ \\
\hline \multicolumn{7}{|l|}{ Cultivar (C) } \\
\hline IAC 3 & $294 \mathrm{~d}$ & $187 \mathrm{f}$ & $2,21 \mathrm{a}$ & $1,48 \mathrm{c}$ & $43 \mathrm{~d}$ & $62 \mathrm{~d}$ \\
\hline IAC 364 & $543 \mathrm{~b}$ & 502 c & $1,55 \mathrm{~b}$ & $3,19 \mathrm{a}$ & 366 a & $309 \mathrm{~b}$ \\
\hline IAC 370 & $558 \mathrm{~b}$ & $468 \mathrm{~d}$ & $1,69 \mathrm{~b}$ & $2,87 \mathrm{a}$ & $288 \mathrm{~b}$ & $253 c$ \\
\hline EMBRAPA 22 & $609 a$ & $538 \mathrm{~b}$ & $0,76 \mathrm{c}$ & $1,88 \mathrm{~b}$ & $313 \mathrm{~b}$ & $325 a b$ \\
\hline BRS 210 & $628 \mathrm{a}$ & 568 a & $1,79 \mathrm{~b}$ & $2,22 \mathrm{~b}$ & $217 c$ & 358 a \\
\hline BRS 207 & $500 \mathrm{c}$ & $354 \mathrm{e}$ & $1,71 \mathrm{~b}$ & $1,46 \mathrm{c}$ & 192 c & $270 \mathrm{c}$ \\
\hline Teste F (Cultivar) & $237,71^{* *}$ & $850,73^{* *}$ & $60,94^{* *}$ & $84,77^{* *}$ & $474,59^{* *}$ & $190,20^{* *}$ \\
\hline D.M.S. (Tukey a 5\%) & 38,43 & 24,05 & 0,3013 & 0,3845 & 25,77 & 37,58 \\
\hline \multicolumn{7}{|l|}{ Doses de $N\left(\mathrm{~kg} \mathrm{ha}^{-1}\right)(\mathrm{D})$} \\
\hline 0 & 500 & 410 & 1,96 & 2,17 & 199 & 215 \\
\hline 30 & 523 & 419 & 1,70 & 2,65 & 213 & 220 \\
\hline 60 & 521 & 439 & 1,55 & 2,28 & 253 & 269 \\
\hline 90 & 549 & 459 & 1,47 & 1,93 & 248 & 297 \\
\hline 120 & 518 & 454 & 1,40 & 1,88 & 270 & 313 \\
\hline Teste F (Doses de N) & $7,95^{* *}$ & $27,64^{* *}$ & $13,57^{* *}$ & $26,32^{* *}$ & $63,15^{* *}$ & $62,16^{* *}$ \\
\hline Teste F (Interação C x D) & $10,46^{* *}$ & $10,26^{* *}$ & $5,72^{* *}$ & $4,50^{* *}$ & $4,65^{* *}$ & $5,12^{* *}$ \\
\hline C.V. $(\%)$ Cultivar & 5,8 & 4,4 & 14,7 & 13,9 & 8,6 & 11,3 \\
\hline C.V. $(\%)$ Doses de N & 5,1 & 3,9 & 15,8 & 11,7 & 6,7 & 9,1 \\
\hline
\end{tabular}

Médias seguidas da mesma letra não diferem entre si pelo teste de Tukey a $5 \%$ de probabilidade.

** = significativo a $1 \%$ de probabilidade pelo teste $\mathrm{F}$, respectivamente.

Com a adubação nitrogenada, a força geral do glúten (W) aumentou linearmente em todas as cultivares de trigo nas duas safras (Figuras 3e e 3f), exceto para triticale (IAC 3) na safra de 2004. A IAC 364 revelou a maior força geral do glúten para todas as doses de N na safra de 2004 e o BRS 210 na safra de 2005. Também Borghi et al. (1994), GUARIENTI et al. (1994a) e SOARES SOBRINHO (1999) verificaram aumento da força geral do glúten com o fornecimento da adubação nitrogenada. De acordo com a classificação de Rosa e Rosa Filho (1998), na safra de 2004, as cultivares IAC 364, IAC 370 e EMBRAPA 22 seriam classificadas como trigos com farinha de classe melhoradora e o BRS 210 e BRS 207 como trigo com farinha de classe pão na maior dose de $\mathrm{N}$ aplicado em cobertura (120 kg ha-1); já na safra de 2005, todas as cultivares seriam classificadas como trigo com farinha de classe melhoradora na maior dose de $\mathrm{N}$ aplicado em cobertura, com exceção do triticale, que nas duas safras seria classificado como farinha para outros usos.

\section{CONCLUSÕES}

1. O peso hectolítrico do triticale foi inferior ao das cultivares de trigo, com a adubação nitrogenada proporcionando redução nesse componente.

2. O número de queda foi adequado, sendo pouco afetado pela adubação nitrogenada;

3. A relação P/L da farinha, de forma geral, foi elevada, podendo prejudicar a aceitação comercial de farinha para panificação.

4. A adubação nitrogenada em cobertura incrementou a força geral do glúten $(W)$, bem como o teor de proteína da farinha e reduziu a relação $\mathrm{P} / \mathrm{L}$, influenciando positivamente na qualidade da farinha para panificação.

5. A farinha de triticale não foi adequada para fins de panificação, por sua reduzida força geral do glúten. 


\section{AGRADECIMENTO}

Os autores agradecem à FAPESP pelo financiamento do Projeto.

\section{REFERÊNCIAS}

BORGHI, B.; CORBELLINI, M.; MINOIA, C.; BOGGIN, G.; FONZO, N., PERENZIN, M.; DI-FONZO, N.; BORIN, M.; SATTIN, M. Effects of mediterranean climate on wheat bread making quality. Proceedings on the third congress European Society for Agronomy, Abono Padova, Italy, p.584-585, 1994.

BRASIL. Ministério da Agricultura, do Abastecimento e da Reforma Agrária. Instrução normativa n.1, de 27 de janeiro de 1999. Diário Oficial da União (da República Federativa do Brasil), Brasília, n.20, p.132-134, 29 de janeiro 1999. Seção 1.

CAMARGO, C.E.O.; FELÍCIO, J.C.; PETTINELLI JUNIOR, A.; ROCCHA JUNIOR, L.S. Adubação nitrogenada em cultura do trigo irrigada por aspersão no Estado de São Paulo. Campinas: Instituto Agronômico, 1988. 62p. (Boletim científico, 15)

CAMARGO, C.E.O.; FREITAS, J.G.; CANTARELLA, H. Recomendações de adubação e calagem para o trigo e triticale irrigados. In: RAIJ, B. van; CANTARELLA, H.; QUAGGIO, J. A.; FURLANI, A.M.C. (Ed.). Recomendações de Adubação e Calagem para o Estado de São Paulo. Campinas: IAC, 1997, p.70-71 (Boletim Técnico, 100)

COELHO, M.A.O.; SOUZA, M.A.; SEDIYAMA, T.; RIBEIRO, A.C.; SEDIYAMA, C.S. Resposta da produtividade de grãos e outras características agronômicas do trigo EMBRAPA-22 irrigado ao nitrogênio em cobertura. Revista Brasileira de Ciências do Solo, Campinas, v.22, n.3, p.555-561, 1998.

COELHO, M.A.O.; SEDIYAMA, T.; SOUZA, M.A.; RIBEIRO, A.C.; SEDIYAMA, C.S. Composição mineral e exportação de nutrientes pelos grãos do trigo irrigado e submetido a doses crescentes e parceladas de adubo nitrogenado. Revista Ceres, Viçosa, v. 48, n. 275, p.81-84, 2001.

COOPER, J. L.; BLAKENEY, A. B. The effect of two forms of nitrogen fertilizer applied near anthesis on the grain quality of irrigated wheat. Australian Journal of Experimental Agriculture, Melbourne, v. 30, n.5, p.611-615, 1990.

EMPRESA BRASILEIRA DE PESQUISA AGROPECUÁRIA. EMBRAPA. Sistema brasileiro de Classificação dos Solos. Rio de Janeiro: EMBRAPA/CNPSO, 1999. 412p.

EMPRESA BRASILEIRA DE PESQUISA AGROPECUÁRIA. EMBRAPA. Sistema de Produção de trigo no Brasil Central, 2002. Disponível em: <http://www.cnpt.embrapa.br/sitprod/trigo-central02/index.htm>.Acesso em: 8 set. 2003.

FRIZONE,J.A.;MÉLLOJÚNIOR, A.V.;FOLEGATTI,M.V.;BOTREL, T. A. Efeito de diferentes níveis de irrigação e adubação nitrogenada sobre componentes de produtividade da cultura do trigo. Pesquisa Agropecuária Brasileira, Brasília, v.31, n.6, p.425-434, 1996.

GUARIENTI, E. M. Qualidade industrial do trigo. Passo Fundo: EMBRAPA/CNPT,1993.27p. (EMBRAPA -CNPT Documentos, 8).
GUARIENTI, E. M.; BASSOI, M. C.; DOTTO, S. R. Efeitos de doses de nitrogênio sobre características de qualidade industrial de cultivares de trigo recomendadas para plantio no Paraná. In: REUNIÃO NACIONAL DE PESQUISA DE TRIGO, 17, 1994, Passo Fundo, Resumo... Passo Fundo: EMBRAPA- CNPT, 1994a, p.176.

GUARIENTI, E. M.; SANTOS, H. P.; LHAMBY, J. C. B. Influencia do manejo do solo e da rotação de culturas na qualidade industrial do trigo. Pesquisa Agropecuária Brasileira. Brasília, v.35, n.12, p.2375-2382, 2000.

GUARIENTI, E. M.; WIETHOLTLER, S.; PERRUZO, G.; CIPRANDI, M. A. O. Influência de nitrogênio em características de qualidade industrial de trigo. In: REUNIÃO NACIONAL DE PESQUISA DE TRIGO, 17, 1994, Passo Fundo, Resumo... Passo Fundo: EMBRAPA- CNPT, 1994b, p.178.

LOEWY, T. Nitrogen fertilizer application on wheat in south western Buenos Yirse Province. II. Response of grain quality. Ciencia del Suelo, Buenos Aires, v.8, n.1, p.57-65, 1990.

MANDARINO, J.M.G. Aspectos importantes para a qualidade do trigo. Londrina: EMBRAPA/CNPSo, 1993.32p. (EMBRAPA/ CNPSo. Documentos, 60)

MANDARINO, J. M. G. Componentes do trigo: características físico-químicas, funcionais e tecnológicas, Londrina: EMBRAPA/CNPSo, 1994. 36p. (EMBRAPA/CNPSo. Documentos, 75)

PELTONEN, J. Ear developmental stage used for timing supplemental nitrogen application to spring wheat. Crop Science, Madison, v.32, n.4, p.1029-1033, 1992.

PEREIRA, P. C. V.; VELINI, E. D.; MACHADO, J. F. Efeito de doses de nitrogênio e do fitoregulador uniconazole, sobre a produtividade da cultura do trigo, cultivar IAC-5. In: REUNIÃO NACIONAL DE PESQUISA DE TRIGO, 16, 1991, Dourados - MS. Resumos... EMBRAPA-UEPAE de Dourados, Dourados, 1991, p.43.

PURI, Y.P.; MILLER, M. F.;SAH, R. N. BAGHOT, K. G.; CASTEL, E. F.; MEYER, R. D. Response surface analysis of the effects of seedong rates, N - rates and irrigation. II. Protein yield and grain quality. Phyton, Buenos Aires, v.49, n.1-2, p.41-59, 1989.

RAIJ, B. van; QUAGGIO, J.A. Métodos de análise de solo para fins de fertilidade. Campinas: Instituto Agronômico, 1983. 31p. (Boletim técnico, B1)

ROSA, O.S.; ROSA FILHO, O. Trigo brasileiro: acredite nessa idéia. Correio Agrícola - Bayer, São Paulo, n.1, p.8-12, 1998.

SOARESSOBRINHO, J. Efeito de doses de nitrogênio e de lâminas de água sobre as características agronômicas e industriais em duas cultivares de trigo (Triticum aestivum L.). 102p. Tese (Doutorado em Produção Vegetal) - Faculdade de Ciências Agrárias e Veterinárias, Universidade Estadual Paulista, Jaboticabal, 1999.

SOAVE, D.; FREITAS, J.G. Eficiência e resposta de genótipos de trigo a doses de nitrogênio em relação ao teor e à qualidade de proteína Bruta. Revista de Agricultura, Piracicaba, v.71, n.1, p.135-144, 1996. 